\title{
Differential effect of transdermal estrogen plus progestagen replacement therapy on insulin metabolism in postmenopausal women: relation to their insulinemic secretion
}

\author{
Francesco Cucinelli, Pierluigi Paparella, Liberato Soranna, Angela Barini ${ }^{1}$, Biagio Cinque, Salvatore Mancuso \\ and Antonio Lanzone ${ }^{2}$ \\ Department of Obstetrics and Gynecology, ${ }^{1}$ Biological Chemistry, Università Cattolica S. Cuore, Largo Gemelli 8, O0168 Rome, Italy and \\ ${ }^{2}$ OASI Institute for Research, Troina, Italy \\ (Correspondence should be addressed to A Lanzone, Department of Obstetrics and Gynecology, Università Cattolica S. Cuore, Largo Gemelli 8, \\ 00168 Rome, Italy)
}

\begin{abstract}
Objective: To evaluate the impact on glucose and insulin metabolism of transdermal estrogen patches before and after the addition of cyclic dydrogesterone in postmenopausal women.

Design: We studied 21 postmenopausal women seeking treatment for symptomatic menopause. All patients received transdermal $50 \mu \mathrm{g} /$ day estradiol for 24 weeks. After 12 weeks of treatment, $10 \mathrm{mg} /$ day dydrogesterone were added.

Methods: During both regimens, insulin and C-peptide plasma concentrations were evaluated after an oral glucose tolerance test (OGTT); insulin sensitivity was evaluated by a hyperinsulinemic euglycemic clamp technique. Insulin and C-peptide response to OGTT were expressed as area under the curve (AUC) and as incremental AUC; insulin sensitivity was expressed as $\mathrm{mg} / \mathrm{kg}$ body weight. Fractional hepatic insulin extraction (FHIE) was estimated by the difference between the incremental AUC of the C-peptide and insulin divided by the incremental AUC of the C-peptide. Plasma hormone and lipid concentrations were assessed at baseline and at 12 and 24 weeks of treatment.

Results: Nine patients proved to be hyperinsulinemic and 12 were normoinsulinemic. Transdermal estrogen treatment significantly decreased the insulin AUC $(P<0.05)$ and the insulin incremental AUC in hyperinsulinemic patients; addition of dydrogesterone further decreased both the AUC and incremental AUC of insulin. Estrogen alone and combined with dydrogesterone evoked a significant increase in C-peptide AUC in hyperinsulinemic (79.2\%) and normoinsulinemic $(113 \%)$ patients. The treatment increased the values for FHIE and insulin sensitivity in all patients $(P<0.04)$ and in the hyperinsulinemic group $(P<0.01)$, whereas it did not affect such parameters in normoinsulinemic patients.

Conclusions: Transdermal estrogen substitution alone and combined with cyclical dydrogesterone may ameliorate hyperinsulinemia in a selected population of postmenopausal women.
\end{abstract}

European Journal of Endocrinology 140 215-223

\section{Introduction}

There are conflicting data on the impact of the menopause on glucose metabolism: earlier studies reported a deterioration in glucose tolerance and an increase in plasma insulin $(1,2)$, whereas other investigations found no significant changes in carbohydrate metabolism $(3,4)$.

It has been suggested that estrogen replacement therapy (ERT) improves insulin sensitivity and is able to decrease fasting insulin concentrations without a deterioration in glucose homeostasis (5). In a prospective randomized cross-over study over 3 months, unopposed supraphysiological doses of ERT had no effect on glucose tolerance or insulin sensitivity in postmenopausal women (6).

Recently, concern has been expressed regarding the potential negative metabolic impact of the addition of progestin to ERT. Although, in female rats, progesterone seemed to antagonize the action of insulin on tissues (7), some authors (8) concluded that the addition of progestin did not appear to attenuate the possible benefits of ERT. Moreover, human studies on metabolic changes provided the existence of a heterogenous pattern of carbohydrate metabolism in postmenopausal women.

In this prospective study, the effect on glucose and insulin metabolism of physiological transdermal estrogen replacement combined with dydrogesterone was studied in postmenopausal women and analyzed in relation to their metabolic status, particularly that of insulin secretion.

\section{Materials and methods}

After screening, 21 healthy white postmenopausal women aged 46-58 years, who were attending the 
Gynecologic Department of our University for the relief of menopausal symptoms, entered the study protocol. Women were between 1 and 5 years postmenopausal; none had undergone hysterectomy or bilateral oophorectomy. Prior to the women's entry to the study, assessment of plasma follicle-stimulating hormone $($ FSH $>50 \mathrm{IU} / \mathrm{l})$ and $17-\beta$-estradiol $(<10 \mathrm{pg} / \mathrm{ml})$ concentrations, mammography, transvaginal ultrasound examination, cervical cytology and hysteroscopic endometrial biopsy were performed and found to be normal or compatible with menopausal status. No patient was currently taking drugs known to affect lipid or glucose metabolism, nor had they taken any steroid within the previous 6 months. None smoked more than 10 cigarettes/day or drank more than $300 \mathrm{~g}$ alcohol/week. Diabetes or impairment of glucose tolerance, breast cancer, altered liver or kidney parameters, history of major thromboembolism, thyroid disease and uncontrolled or $\beta$-blocker-treated hypertension (systolic blood pressure greater than $160 \mathrm{mmHg}$ or diastolic pressure greater than $90 \mathrm{mmHg}$ ) were considered exclusion criteria. The study was approved by the Ethics Committee of our University. Informed consent was obtained from each woman.

Estrogen patches delivering transdermal $50 \mu \mathrm{g} 17-\beta$ estradiol daily, were administered to each woman (Epiestrol 50; Roerig Farmaceticals, Latina, Italy) for 24 weeks. Patches were changed twice weekly. After 12 weeks of unopposed continuous estrogen therapy, cyclic dydrogesterone $10 \mathrm{mg}$ /day orally (Duphaston; Solvay Duphar BV, Weesp, The Netherlands), added for 12 days of each 28-day cycle (from day 10 to day 21) was continued until the end of the study. The dosage of transdermal compound was chosen in the light of published data showing it to be near the range of the physiological activity of estrogens during the menstrual cycle (9).

Women attended the Obstetrics and Gynecologic Unit before and at 12 weeks and 24 weeks after the start of the study. An oral glucose tolerance test (OGTT) and a hyperinsulinemic euglycemic clamp were performed before treatment, at 12 weeks of estrogen treatment before the addition of progestin, and during the second week of the last cycle of progestin coadministration. At the same time, FSH, luteinizing hormone (LH), prolactin, 17$\beta$-estradiol, estrone, cortisol, dehydroepiandrosterone sulfate (DHEAS), androstenedione, 17-hydroxyprogesterone (17-OHP), testosterone, sex hormone-binding globulin (SHBG), low-density lipoprotein (LDL-C), high-density lipoprotein (HDL-C) and very-low-density lipoprotein (VLDL-C) cholesterols, and non-esterified fatty acids (NEFA), together with an evaluation of the coagulation profile, were assayed. Each time, the women were admitted to hospital and an ultrasonographic pelvic evaluation was performed to monitor the endometrium and ovaries.

The OGTTs were performed, as follows, after the patient had followed a standard carbohydrate diet (300 g/day) for 3 days and fasted overnight for 10-12 h. At $0800 \mathrm{~h}$, an indwelling catheter was inserted into the antecubital vein of one arm and flushed with heparinized saline solution. Basal blood samples were collected at 0 and 30 , $60,90,120,180$ and $240 \mathrm{~min}$ after the ingestion, within $5 \mathrm{~min}$, of $75 \mathrm{~g}$ glucose in $150 \mathrm{ml}$ water. In all samples, glucose, insulin and C-peptide plasma concentrations were determined; in basal blood samples, other hormonal and biochemical assays were also performed.

Insulin sensitivity was assessed by the use of the hyperinsulinemic euglycemic clamp technique (10). The test was performed 2 days after the OGTT, after a 12-h overnight fast. A retrograde intravenous catheter was inserted into a hand or forearm vein for blood sampling and kept in a warming device at $60^{\circ} \mathrm{C}$ to arterialize the venous blood samples. Another indwelling catheter was inserted in the contralateral forearm vein (Cavafix, B Braun, Melsungen, Germany) for the glucose and insulin infusions. A two-step, primed, constant infusion of human insulin (Actrapid HM, Novo Nordisk, Bagsvaerd, Denmark) was administered at a rate of $40 \mathrm{mIU} / \mathrm{m}^{2}$ per min. Within $10 \mathrm{~min}$ after a steady state velocity of insulin infusion was reached, in order to achieve steady-state insulin circulatory concentrations of about $717 \mathrm{pmol} / \mathrm{l}$ during the clamp (range 574$897 \mathrm{pmol} / \mathrm{l}$ ), a variable infusion of $20 \%$ glucose was begun via a separate infusion pump. Blood samples were taken from the arterialized line every $5 \mathrm{~min}$, and blood glucose concentrations were immediately measured on a glucose analyzer. The exogenous glucose infusion was adjusted according to a standard algorithm to maintain the blood glucose concentration between 4.4 and $4.9 \mathrm{mmol} / \mathrm{l}$.

Anthropometric measurements (height and weight) were obtained to calculate body mass index (BMI; $\mathrm{kg} / \mathrm{m}^{2}$ ). Patients with a BMI of $25 \mathrm{~kg} / \mathrm{m}^{2}$ or greater were defined as obese; this cut-off point was approximately at the median. Waist: hip ratio (WHR) was measured as the ratio of the waist circumference to that of the hip. Samples for measurement of plasma glucose concentrations and biochemical parameters were assayed immediately; samples for measurement of basal and stimulated insulin and C-peptide, together with other hormones, were centrifuged promptly and the plasma stored at $-20^{\circ} \mathrm{C}$ until required for assay.

All hormones were measured by commercial RIA kits (Radim, Pomezia, Italy). The intra- and interassay coefficients of variation were less than $8 \%$ and $15 \%$ for all hormones, respectively. The cross-reactivity of pro-insulin in the radioimmunoassay for insulin was about $40 \%$.

Plasma glucose concentrations were determined by the glucose oxidase technique, using an $\alpha$ glucose analyzer (Beckman Instruments, Palo Alto, CA, USA). Plasma total cholesterol and triglyceride concentrations were measured using commercially available kits. VLDL-C was separated (as supernatant) from LDL-C and HDL-C by ultracentrifugation of native lipoprotein. 
NEFA were determined by an acyl coenzyme-A oxidasebased colorimetric method.

A normal glycemic response to OGTT was defined according to the criteria of the National Diabetes Data Group (11). Glucose, insulin and C-peptide plasma concentrations were expressed as fasting values and as time courses over $240 \mathrm{~min}$ after glucose load; insulin and C-peptide were also expressed as area under the curve (AUC) after glucose load, calculated by the trapezoidal rule. The incremental AUC for both insulin and C-peptide was calculated by the difference between AUC and basal AUC (basal AUC = area of the curve theoretically due to the fasting value per $240 \mathrm{~min}$ ). The patients were classified as normo- or hyperinsulinemic according to their insulin response to OGTT, assuming an AUC cut-off value of $107625 \mathrm{pmol} / \mathrm{l}$ per $240 \mathrm{~min}$, as previously described (12).

Pancreatic insulin secretion was analyzed on the basis of C-peptide concentration measures, because of its equimolar secretion with insulin and its negligible hepatic metabolism (13).

Fractional hepatic insulin exctraction (FHIE) was estimated by the difference between the incremental AUC of the C-peptide and insulin divided by the incremental AUC of the C-peptide (14).

Insulin sensitivity (M value) was calculated as total body glucose utilization, determined between 60 and $240 \mathrm{~min}$ of the glucose clamp, and expressed as $\mathrm{mg} / \mathrm{kg}$ body weight per min. because the $\mathrm{M}$ value/insulin ratio fails to narrow the range of the individual sensitivity values (15).

Data were stored and analyzed using SPSS (Statistical Package for Social Science; release 5.0) on an IBMcompatible computer. A Kolmogorov-Smirnov test was performed to asses differences in the general shapes of the distributions. In accordance with the non-parametric distribution of the studied population, data were analyzed as median and range, but expressed as media and standard error (s.e.).

A value of $P<0.05$ was considered to be significant. Differences between baseline and treatments were analyzed by one-way analysis of variance (ANOVA) and Scheffe's test for post-hoc comparisons. The MannWhitney $U$ test was used to assess differences between independent samples.

Correlation between variables was calculated by a bivariate analysis according to Spearman.

\section{Results}

All patients recruited completed the study protocol. On the basis of their insulinemic response to OGTT, nine patients $(43 \%)$ were hyperinsulinemic and $12(57 \%)$ were normoinsulinemic. No difference in glomerular filtration was observed between the groups and in relation to treatments. No patient developed skin irritation, bleeding disturbances or mastalgia. Blood pressure remained stable during treatment compared with pretreatment values, and no changes in dietary habits were reported to occur during the study. BMI and WHR values were similar among the two groups, and no change was reported during treatment. The fasting glucose plasma concentration was unchanged with respect to baseline after estrogen alone or after estrogen-progestin combined therapy, and no differences were found between hyper- and normoinsulinemic groups (Table 1). Neither estrogen alone nor the estrogen-progestin combined regimen affected fasting

\begin{tabular}{|c|c|c|c|}
\hline & $a$ & $b$ & $c$ \\
\hline $\begin{array}{l}\text { All } \\
\text { WHR } \\
\text { BMI }\left(\mathrm{kg} / \mathrm{m}^{2}\right) \\
\text { Fasting glucose }(\mathrm{mmol} / \mathrm{l}) \\
\text { Fasting insulin }(\mathrm{pmol} / \mathrm{l}) \\
\text { Fasting C-peptide }(\mathrm{pmol} / \mathrm{l})\end{array}$ & $\begin{array}{c}0.84 \pm 0.016 \\
26.8 \pm 1.1 \\
4.81 \pm 0.1 \\
76.3 \pm 57.2 \\
453.5 \pm 86.1\end{array}$ & $\begin{array}{c}27.1 \pm 1.4 \\
4.8 \pm 0.1 \\
74.7 \pm 13.7 \\
695.1 \pm 95.6 \neq\end{array}$ & $\begin{array}{c}0.83 \pm 0.019 \\
26.9 \pm 1.2 \\
4.7 \pm 0.1 \\
75.4 \pm 12.4 \\
697.4 \pm 69.2 \S\end{array}$ \\
\hline $\begin{array}{l}\text { Hyperinsulinemic } \\
\text { WHR } \\
\text { BMI }\left(\mathrm{kg} / \mathrm{m}^{2}\right) \\
\text { Fasting glucose }(\mathrm{mmol} / \mathrm{l}) \\
\text { Fasting insulin }(\mathrm{pmol} / \mathrm{l}) \\
\text { Fasting C-peptide }(\mathrm{pmol} / \mathrm{l})\end{array}$ & $\begin{array}{c}0.84 \pm 0.017 \\
28.5 \pm 2.5 \\
4.83 \pm 0.1 \\
118.1 \pm 25.5 \\
590.8 \pm 160.9\end{array}$ & $\begin{array}{c}28.2 \pm 1.6 \\
4.9 \pm 0.3 \\
93.9 \pm 27.8 \\
873.2 \pm 175.8 \ddagger\end{array}$ & $\begin{aligned} 0.85 & \pm 0.018 \\
28.5 & \pm 1.1 \\
4.7 & \pm 0.1 \\
102.2 & \pm 19.6 \\
668.6 & \pm 46 \S\end{aligned}$ \\
\hline $\begin{array}{l}\text { Normoinsulinemic } \\
\text { WHR } \\
\text { BMI }\left(\mathrm{kg} / \mathrm{m}^{2}\right) \\
\text { Fasting glucose }(\mathrm{mmol} / \mathrm{l}) \\
\text { Fasting insulin }(\mathrm{pmol} / \mathrm{l}) \\
\text { Fasting C-peptide }(\mathrm{pmol} / \mathrm{l})\end{array}$ & $\begin{array}{c}0.83 \pm 0.027 \\
25.8 \pm 1.1 \\
4.8 \pm 0.1 \\
51.2 \pm 3.9 \\
378.9 \pm 101.6\end{array}$ & $\begin{array}{c}26.1 \pm 1.2 \\
4.7 \pm 1.7 \\
61.8 \pm 13.2 \\
576.3 \pm 100.6\end{array}$ & $\begin{array}{c}0.83 \pm 0.025 \\
26.2 \pm 1.3 \\
4.7 \pm 0.2 \\
60.5 \pm 14.3 \\
713.3 \pm 106.9 \S\end{array}$ \\
\hline
\end{tabular}

$\ddagger P<0.05, \boldsymbol{b}$ compared with $\boldsymbol{a}$; $\S P<0.05, \boldsymbol{c}$ compared with $\boldsymbol{a}$. 
insulin plasma concentrations in all the groups studied. At 12 and 24 weeks of treatment, all studied groups, and the hyperinsulinemic patients, showed significantly greater $\mathrm{C}$-peptide plasma concentrations compared with those observed before treatment $(P<0.05)$; the addition of progestin did not reverse these concentrations to the pretreatment values. Neither estrogen alone nor estrogen-progestin combined affected glucose plasma concentrations, as shown by the time courses of glucose concentration after the glucose load (Fig. 1).

Figure 2 shows the insulin response to OGTT expressed as time courses of insulin concentration over $240 \mathrm{~min}$ after the glucose load and as AUC and incremental AUC before and during the two-step treatments in all patients studied. It can be seen that, in the entire study population and in the normoinsulinemic women, both treatments failed to affect significantly the insulin AUC or incremental AUC compared with pretreatment values. However, hyperinsulinemic patients treated with transdermal estradiol demonstrated a significant decrease in plasma insulin at 60, 90 and $120 \mathrm{~min}(P<0.05)$ and in insulin AUC $(P<0.05)$; the addition of dydrogesterone further decreased both the insulin AUC (by 14\% with respect to that produced by estrogen alone) and the insulin incremental AUC. The overall effect of treatment in the hyperinsulinemic group resulted in a statistically significant decrease in both insulin plasma concentrations after the glucose load at 60, 90 and $120 \mathrm{~min}$, in the insulin AUC $(P<0.02)$, and in insulin incremental AUC $(P<0.04)$. These parameters, which before treatment had significantly greater values in the hyper- than in the normoinsulinemic group $(P<0.001$ and $P<0.0001$ respectively), became superimposable in the two groups after 12 and 24 weeks of treatment.

The effect of the scheduled therapy on C-peptide secretion is shown in Fig. 3. Transdermal estrogen treatment induced a highly significant increase in Cpeptide plasma concentrations after the glucose load, in C-peptide AUC $(49 \%, P<0.01)$, and in the incremental AUC of $C$-peptide $(38.5 \%, P<0.05)$; dydrogesterone evoked a further increase in these parameters, even though significance was not achieved in comparison with estrogen alone. A similar C-peptide response to OGTT was seen in hyper- and normoinsulinemic women before treatment. In each group, there was a progressive and significant increase in both parameters. Therefore, the overall effect of treatment was an improvement in C-peptide, either as the time course plasma concentrations after the glucose load or as the AUC (entire study population: $79.5 \%, P<0.01$; hyperinsulinemic group: $79.2 \%, \quad P<0.03$; normoinsulinemic group: $113 \%, \quad P<0.01$ ) and its incremental AUC (all women: $115 \%, \quad P<0.001$; hyperinsulinemic group: $136 \%, P<0.04$; normoinsulinemic group: $56.5 \%$, $P<0.03)$.

Data for FHIE are summarized in Fig. 4. In the hyperinsulinemic group, there were significantly lower

\section{Glucose after OGTT}

All

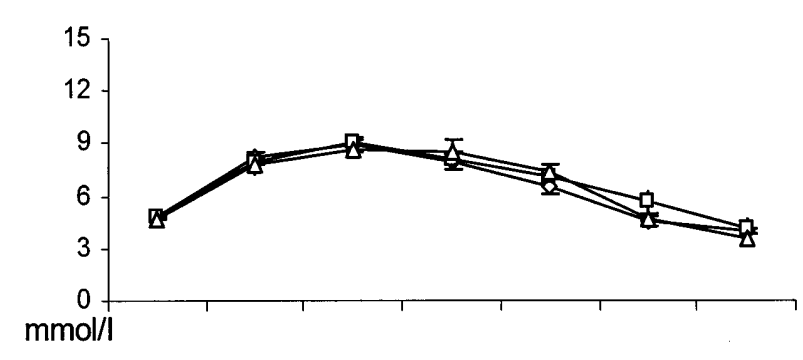

H

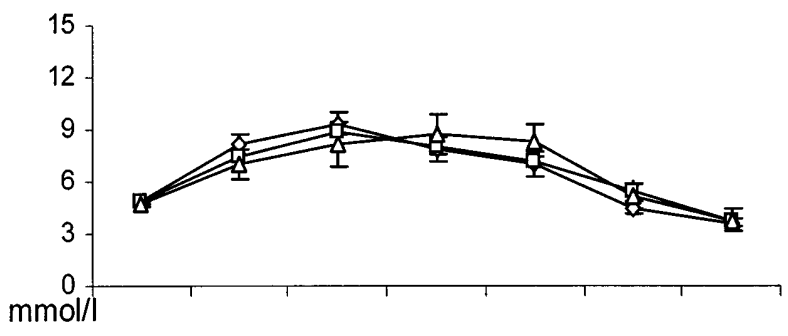

$\mathbf{N}$

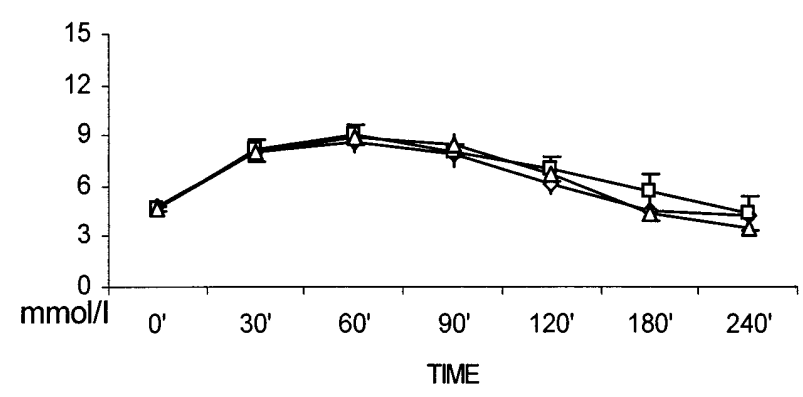

Figure 1 Plasma glucose concentrations expressed as time courses over 240 min after glucose load in the entire study population (All), and the hyperinsulinemic $(\mathrm{H})$ and normoinsulinemic $(N)$ groups of postmenopausal women, before treatment $(\diamond)$, after 12 weeks of unopposed transdermal estrogen therapy $(\square)$ and after 12 weeks of added dydrogesterone $(\triangle)$. Data points represent means \pm S.E. There are no significant inter- or intragroup differences.

baseline values $(P<0.01)$ compared with those in the normoinsulinemic group. After the estrogen regimen, a significant improvement in this parameter was seen in all treated patients $(P<0.05)$ and in hyperinsulinemic patients $(P<0.02)$. Therapy did not affect FHIE in normoinsulinemic women. The overall effect of treatment was superimposable in all the women, and in the hyperinsulinemic group $(P<0.001)$.

Figure 4 also shows the total body glucose utilization ( $\mathrm{M}$ value) in the groups studied. Before treatment, hyperinsulinemic patients showed greater, although not 

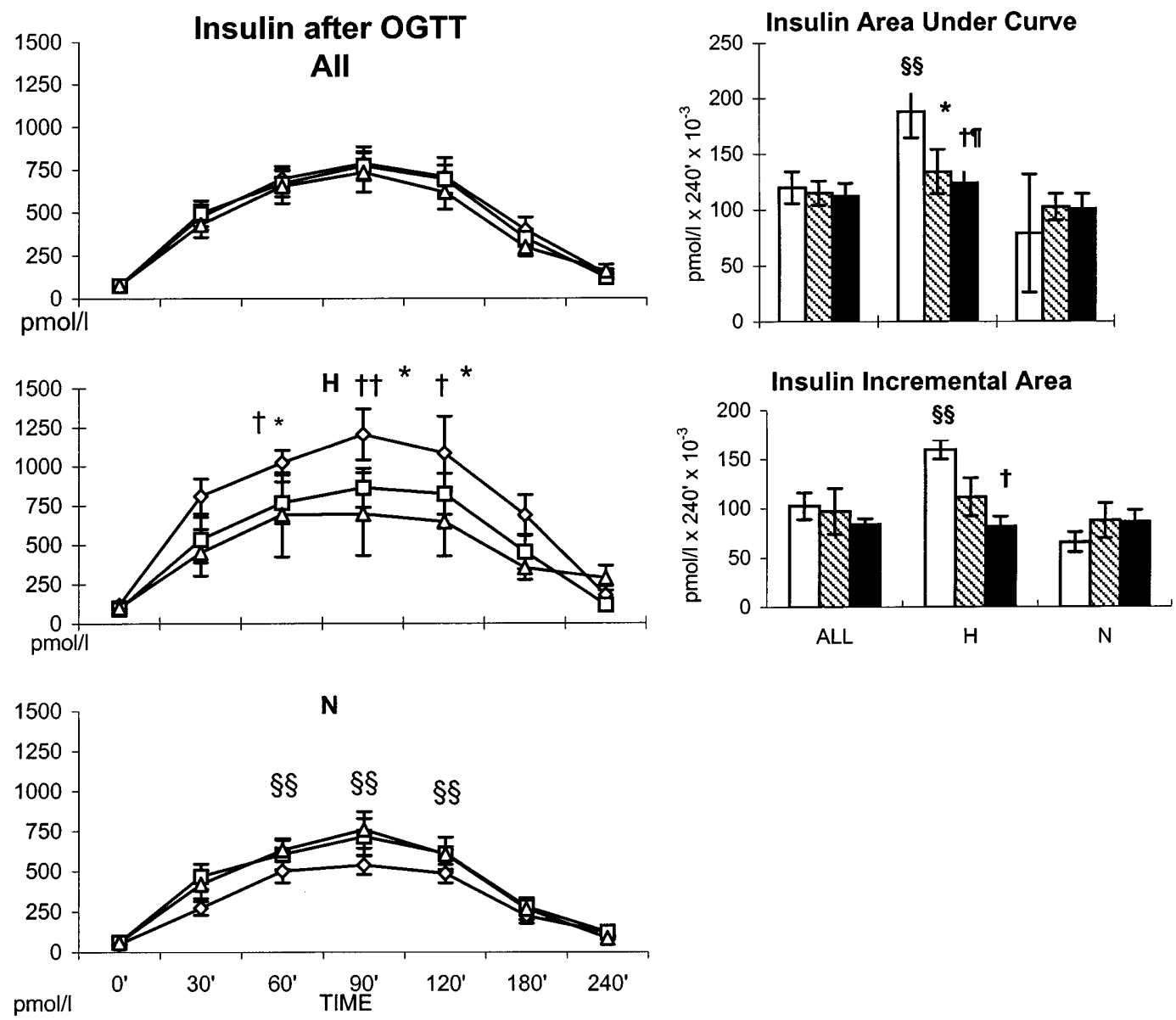

Figure 2 Left: Plasma insulin concentrations expressed as time courses over $240 \mathrm{~min}$ after glucose load in the entire study population (All), and the hyperinsulinemic $(\mathrm{H})$ and normoinsulinemic $(\mathrm{N})$ groups of postmenopausal women, before treatment $(\diamond)$, after 12 weeks of unopposed transdermal estrogen therapy $(\square)$ and after 12 weeks of added dydrogesterone $(\triangle)$. Data points represent means \pm S.E. Intragroup differences: ${ }^{*} P<0.05, \diamond$ compared with $\square ; \dagger P<0.05,+\dagger P<0.01, \Delta$ compared with $\diamond ; \square$ compared with $\triangle$ not significant. Intergroup differences: $\S \S P<0.01$, hyperinsulinemic compared with normoinsulinemic. Right: Insulin AUC and incremental AUC in all studied patients (All), and the hyperinsulinemic $(H)$ and normoinsulinemic $(N)$ groups of postmenopausal women, before treatment $(\square)$, after 12 weeks of unopposed transdermal estrogen therapy $(\mathbb{Q})$ and after 12 weeks of added dydrogesterone $(\square)$. Bars represent means \pm s.E. Intragroup differences: ${ }^{*} P<0.05$ compared with $\square ; \dagger P<0.05$, compared with $\square ; \uparrow P<0.05$, compared with $\mathbb{\mathbb { Q }}$. Intergroup differences: $\S \S P<0.01$, hyperinsulinemic compared with normoinsulinemic.

statistically significant, $\mathrm{M}$ values. Normoinsulinemic patients did not exhibit any improvement in insulin sensitivity during treatment. In contrast, all patients, and the hyperinsulinemic group alone, exhibited a significant increase in $\mathrm{M}$ value at the end of the two-step regimens (all patients: $P<0.04$; hyperinsulinemic group: $P<0.01)$.

Table 2 shows the hormonal and lipidic profiles in the different study groups. Transdermal estrogen treatment significantly reduced FSH $(P<0.05)$ and increased 17 $\beta$-estradiol and estrone plasma concentrations; no net change was detected for these variables after the 12 weeks of additional progestin treatment. Androstenedione and 17-OHP plasma concentrations were not significantly different before and after treatments. DHEAS plasma concentrations decreased significantly after estrogen alone. A significant increase in SHBG plasma concentration was found at 12 and 24 weeks of treatment $(P<0.02)$; no significant changes occurred after the addition of dydrogesterone.

No significant differences were found in the previously cited parameters among the normo- and hyperinsulinemic groups overall during the study, with the exception of greater plasma concentrations of androstenedione and SHBG $(P<0.05)$ at time $c$ in the hyperinsulinemic group than the normoinsulinemic women.

The plasma concentration of cholesterol, LDL-C, triglycerides, HDL-C and VLDL-C did not show any significant variation in relation to the treatments. A superimposable lipidic pattern was observed in the hyper- and normoinsulinemic patients at baseline and 


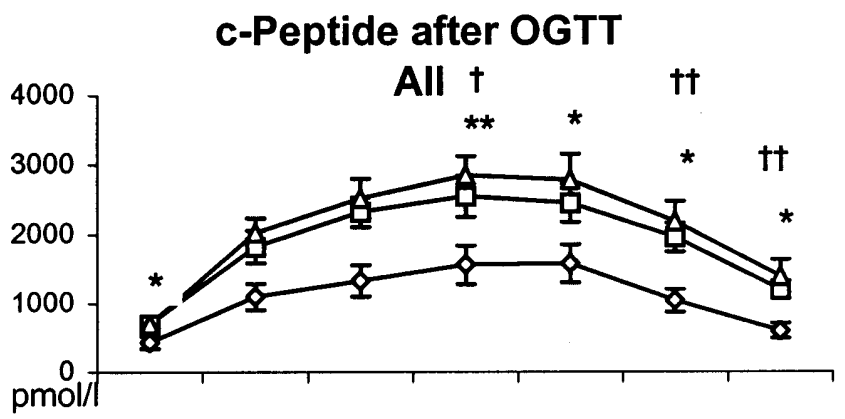

c-Peptide Area Under Curve

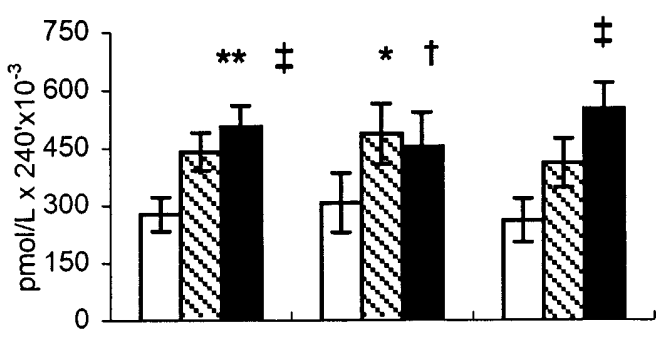

H
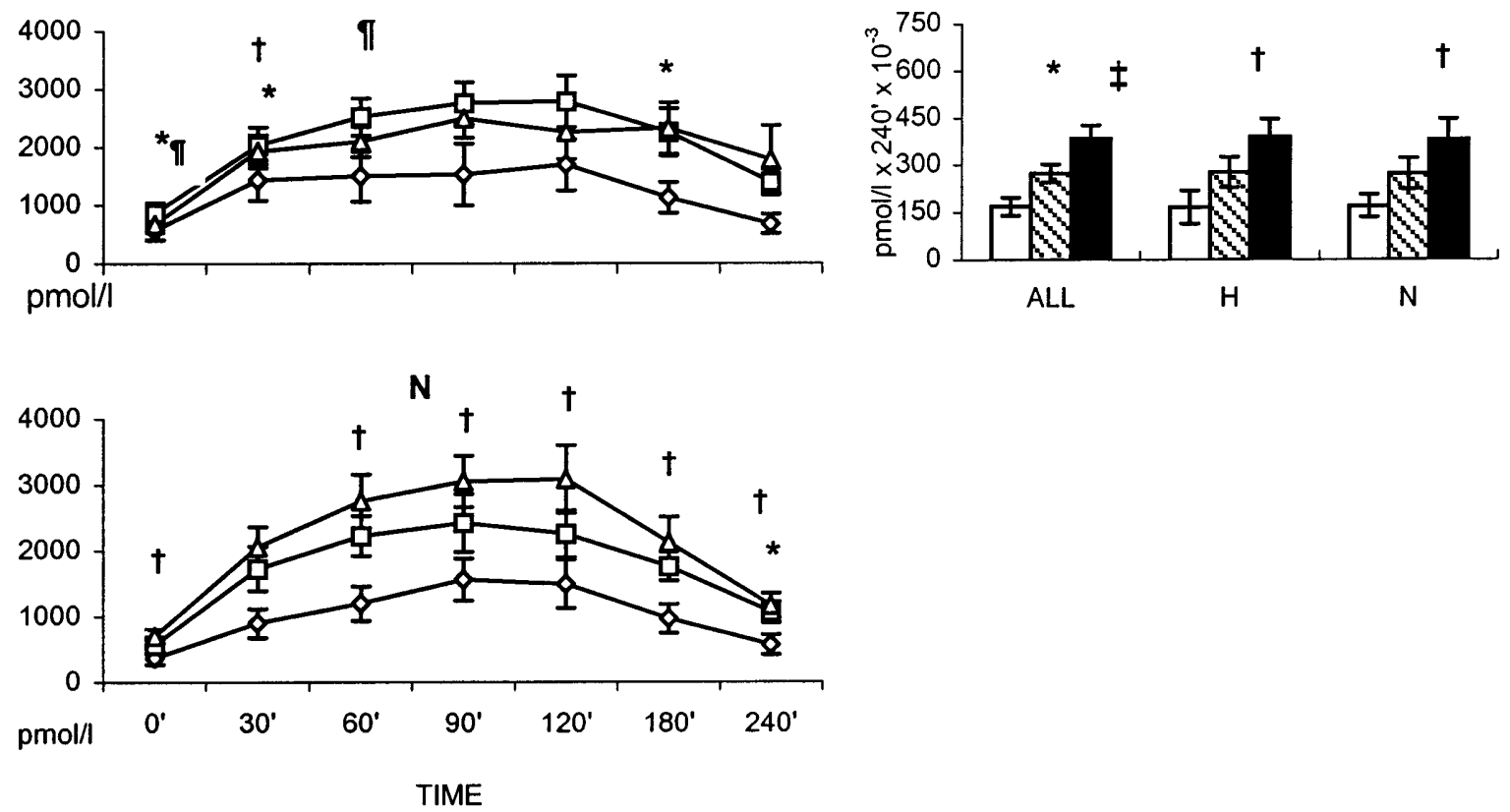

Figure 3 Left: Plasma C-peptide concentrations expressed as time courses over $240 \mathrm{~min}$ after glucose load in the entire study population (All), and the hyperinsulinemic $(\mathrm{H})$ and normoinsulinemic $(\mathrm{N})$ groups of postmenopausal women, before treatment $(\diamond)$, after 12 weeks of unopposed transdermal estrogen therapy $(\square)$ and after 12 weeks of added dydrogesterone $(\triangle)$. Data points represent means \pm S.E. Intragroup differences: ${ }^{*} P<0.05,{ }^{* *} P<0.01, \diamond$ compared with $\square ; \dagger P<0.05, \dagger \dagger P<0.01, \triangle$ compared with $\diamond ; \uparrow P<0.05$, $\square$ compared with $\triangle$. Right: C-peptide AUC and incremental AUC in all studied patients (All), and the hyperinsulinemic $(\mathrm{H})$ and normoinsulinemic $(\mathrm{N})$

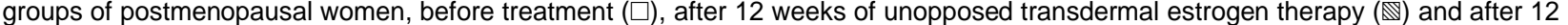
weeks of added dydrogesterone (ם). Bars represent means \pm S.E. Intragroup differences: ${ }^{\star} P<0.05$, ${ }^{\star \star} P<0.01$, compared with $\square$; $\dagger P<0.05, \ddagger P<0.01$, compared with $\square$. Intergroup differences are not significant.

after both estrogen alone and the combined therapy. For additional details see Tables 1 and 2.

\section{Discussion}

Data from retrospective or prospective or longitudinal studies provide extensive and consistent evidence that ERT decreases the risk of coronary heart disease, possibly through the induced changes to the lipidic profile (16-18). Recent in vivo and in vitro studies (19) suggest that the link between the hypothesized beneficial effect of ERT and the suggested effect on the lipidic pattern may be insulin secretion or sensitivity, or both, or glucose-induced re-uptake, which are clearly involved in the pathophysiological mechanism of non-insulin dependent diabetes mellitus (NIDDM), hypertension and coronary heart disease.

There are few studies on the effects of menopause, either surgical or natural, on glucose metabolism and insulin action. In the Framingham study (20), 372 women who underwent menopause were investigated and compared with age-matched premenopausal women; no net change was found in blood glucose. In other studies (21), both fasting glucose and insulin increased more in women who became menopausal than in premenopausal women, although the glucose response to OGTT did not differ. The most detailed evaluation to date (22), indicated that the menopause 
FHIE

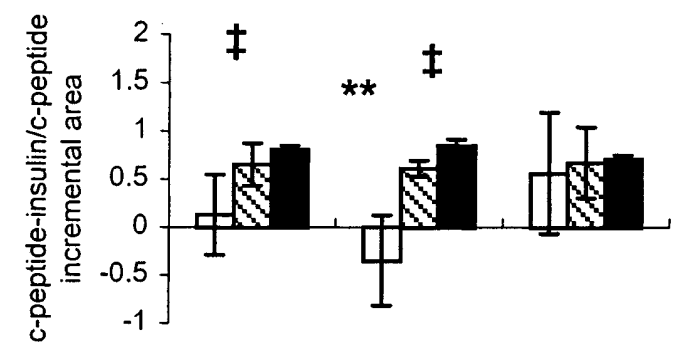

M

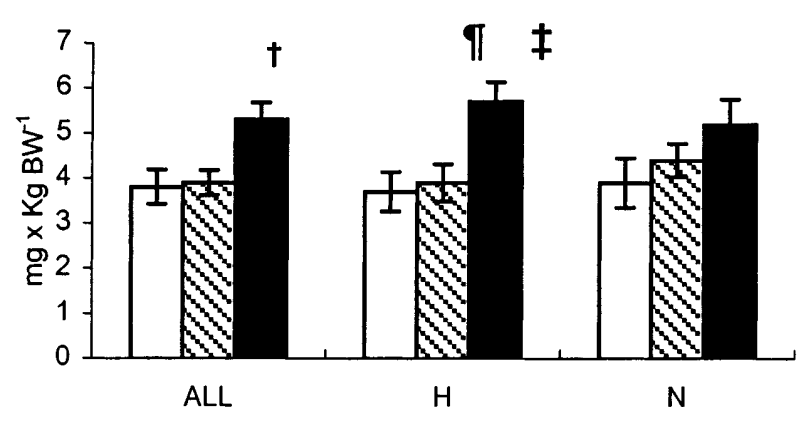

Figure 4 FHIE and $M$ values in all studied patients (All), and the hyperinsulinemic $(\mathrm{H})$ and normoinsulinemic $(\mathrm{N})$ groups of postmenopausal women, before treatment $(\square)$, after 12 weeks of unopposed transdermal estrogen therapy $(\mathbb{\mathbb { Q }})$ and after 12 weeks of added dydrogesterone $(\boldsymbol{\square})$. Bars represent means \pm S.E. Intragroup differences: * $P<0.05$, compared with $\square$; $\uparrow P<0.05$, $¥ P<0.01$, compared with $\square ; \uparrow P<0.05$, compared with $\mathbf{\square}$. Intergroup differences are not significant.

status, per se, is related to a reduced pancreatic insulin response to glucose and a diminished rate of insulin elimination, so that the deficiency in insulin secretion is compensated by a reduced elimination resulting in no net effect on glucose tolerance or insulin plasma concentrations.

When insulin sensitivity was investigated, conflicting results were found, as a result of the standardization of the studied population or the different mathematical modelling analysis used. Detailed evaluations by Lindheim et al. (5) and Godsland et al. (23) revealed a negative correlation between age of menopause and insulin sensitivity or hepatic insulin elimination, or both.

Many published studies have evaluated the influence of estrogen treatment on glucose metabolism. In a recent randomized study, glucose response to OGTT was found to be increased in estrogen-progestin users, but unchanged in an estrogen-alone treatment group. The differences between groups were consistent, with an improved insulin sensitivity in the women taking estrogen alone (24). Conversely, other studies suggested no effects of estrogen therapy on fasting insulin and Cpeptide or OGTT glucose, insulin and C-peptide responses (4).
The results of our study showed that 12 weeks of transdermal estrogen therapy did not affect fasting and OGTT-induced insulin plasma concentrations. Although there was a marked increase in pancreatic C-peptide production, an improvement in FHIE was able to balance the circulating insulin plasma concentrations within the range of normoinsulinemic values. It is interesting to note that addition of dydrogesterone over 12 weeks did not appear to modify the adaptative mechanism leading to unchanged insulinemia, in spite of the increase in pancreatic secretion. A further improvement in FHIE, together with an increased peripheral insulin sensitivity, may explain this phenomenon. Pancreatic C-peptide production and improved FHIE are time-dependent effects of estrogen treatment, and the addition of dydrogesterone does not impair this action.

The most relevant clinical finding of this study is that ERT, hormone replacement therapy (HRT), or both, had differential effects on insulin metabolism in relation to the metabolic status of postmenopausal women. In those patients showing an exaggerated insulin response to OGTT, 12 weeks of transdermal estradiol administration was able to reduce such an insulin response significantly, by $30 \%$; this effect was due to a two- to threefold increase in FHIE, in spite of a concomitant increase in $\beta$-cell activity. Also, when combined with dydrogesterone, transdermal estrogen therapy was able to enhance this trend further towards an amelioration of glucose tolerance, by a further increase in FHIE associated with a significant improvement in the insulin sensitivity.

In the normoinsulinemic group, estrogen substitution did not affect all parameters studied; however, after 24 weeks, with addition of dydrogesterone, a significant increase in $\beta$-cell activity was counteracted by a slight, but not significant, increase in FHIE, which maintained the insulin circulating plasma concentrations unchanged.

In the light of these results, some preliminary conclusions can be drawn, although they need to be confirmed in larger studies. 1) Physiological transdermal estrogen substitution over 24 weeks is associated, in menopausal women, with improved insulin sensitivity. 2) There is evidence for a remarkable increase in pancreatic $\beta$-cell function after 12 weeks of treatment. 3) Fasting and OGTT-induced insulin and glucose plasma concentrations are unaffected by $0.05 \mathrm{mg} /$ day transdermal estrogen, either at 12 or at 24 weeks. 4) The addition of dydrogesterone did not counteract the beneficial effects of estrogen administration on glucose tolerance. This finding is apparently in contrast with data in the literature, as it is known that the use of progestins such as medroxyprogesterone acetate may cause a deterioration in glucose tolerance and insulin resistance, acting through a glucocorticoid-like mechanism that is not seen with progesterone and dydrogesterone $(24,25)$. 5) Hyperinsulinemic women appear to be a population who should be considered for 
Table 2 Lipid and hormonal profile before (a), after 12 weeks of estrogen treatment $(\boldsymbol{b})$ and after dydrogesterone addition $(\boldsymbol{c})$. Values are expressed as means \pm S.E

\begin{tabular}{|c|c|c|c|}
\hline & $a$ & $b$ & $c$ \\
\hline $\begin{array}{l}\text { All } \\
\text { Cholesterol }(\mathrm{mg} / \mathrm{dl}) \\
\text { Trygliceride** }(\mathrm{mg} / \mathrm{dl}) \\
\text { HDL-C }(\mathrm{mg} / \mathrm{dl}) \\
\text { LDL-C }(\mathrm{mg} / \mathrm{dl}) \\
\text { VLDL-C }(\mathrm{mg} / \mathrm{dl}) \\
\text { NEFA }(\mathrm{mEq} / \mathrm{l}) \\
\text { FSH }(\mathrm{IU} / \mathrm{l}) \\
\text { LH }(\mathrm{IU} / \mathrm{l}) \\
\text { Androstenedione }(\mathrm{nmol} / \mathrm{l}) \\
17-O H P(\mathrm{nmol} / \mathrm{l}) \\
\text { DHEAS }(\mu \mathrm{mol} / \mathrm{l}) \\
\text { Estradiol }(\mathrm{pmol} / \mathrm{l}) \\
\text { Estrone }(\mathrm{pmol} / \mathrm{l}) \\
\text { SHBG }(\mathrm{mmol} / \mathrm{l})\end{array}$ & $\begin{aligned} 220.8 & \pm 10.7 \\
133.3 & \pm 13.7 \\
50.1 & \pm 3.0 \\
142.1 & \pm 10.2 \\
27.8 & \pm 2.9 \\
0.37 & \pm 0.02 \\
66.0 & \pm 4.1 \\
44.1 & \pm 3.4 \\
1.86 & \pm 0.3 \\
1.29 & \pm 0.2 \\
1.56 & \pm 0.1 \\
38.3 & \pm 3.4 \\
45.3 & \pm 4.7 \\
39.3 & \pm 3.3\end{aligned}$ & $\begin{array}{c}208.3 \pm 8.7 \\
145.5 \pm 21.5 \\
57.2 \pm 2.1 \\
127.8 \pm 9.2 \ddagger \\
25.1 \pm 2.5 \\
0.32 \pm 0.05 \\
37.1 \pm 3.3 \ddagger \\
31.1 \pm 3.8 \\
2.28 \pm 0.3 \\
1.33 \pm 0.2 \\
1.39 \pm 0.1 \ddagger \\
142.9 \pm 13.9 \ddagger \\
123.2 \pm 20.1 \ddagger \\
62.1 \pm 7.1 \ddagger\end{array}$ & $\begin{aligned} 220.2 & \pm 9.9 \\
158.6 & \pm 26.3 \\
61.3 & \pm 3.8 \\
132.5 & \pm 8.8 \S \\
29.3 & \pm 3.4 \\
0.29 & \pm 0.04 \\
32.2 & \pm 2.6 \S \\
22.8 & \pm 2.5 \\
2.95 & \pm 0.4 \\
1.7 & \pm 0.2 \\
1.21 & \pm 0.1 \S \\
134.7 & \pm 20.0 \S \\
135.8 & \pm 30.6 \S \\
63.3 & \pm 9.3 \S\end{aligned}$ \\
\hline $\begin{array}{l}\text { Hyperinsulinemic } \\
\left.\text { Cholesterol* }^{*} \mathrm{mg} / \mathrm{dl}\right) \\
\text { Trygliceride }^{\star *}(\mathrm{mg} / \mathrm{dl}) \\
\text { HDL-C }(\mathrm{mg} / \mathrm{dl}) \\
\text { LDL-C }(\mathrm{mg} / \mathrm{dl}) \\
\text { VLDL-C }(\mathrm{mg} / \mathrm{dl}) \\
\text { NEFA }(\mathrm{mEq} / \mathrm{l}) \\
\text { FSH }(\mathrm{IU} / \mathrm{l}) \\
\text { LH }(\mathrm{IU} / \mathrm{l}) \\
\text { Androstenedione }(\mathrm{nmol} / \mathrm{l}) \\
17-\mathrm{OHP}(\mathrm{nmol} / \mathrm{l}) \\
\text { DHEAS }(\mu \mathrm{mol} / \mathrm{l}) \\
\text { Estradiol }(\mathrm{pmol} / \mathrm{l}) \\
\text { Estrone }(\mathrm{pmol} / \mathrm{l}) \\
\text { SHBG }(\mathrm{mmol} / \mathrm{l})\end{array}$ & $\begin{array}{c}219.8 \pm 14.6 \\
114.0 \pm 19.3 \\
52.0 \pm 6.0 \\
139.3 \pm 13.0 \\
23.2 \pm 3.2 \\
0.38 \pm 0.01 \\
67.6 \pm 6.7 \\
41.3 \pm 5.9 \\
1.74 \pm 0.5 \\
0.90 \pm 0.2 \\
1.65 \pm 0.2 \\
32.6 \pm 2.93 \\
40.6 \pm 3.0 \\
34.5 \pm 5.7\end{array}$ & $\begin{array}{c}202.5 \pm 14.8 \\
127.8 \pm 21.2 \\
55.3 \pm 4.2 \\
126.6 \pm 11.7 \\
24.5 \pm 3.8 \\
0.28 \pm 0.04 \\
34.3 \pm 5.5 \ddagger \\
29.8 \pm 7.1 \\
2.44 \pm 0.5 \\
1.56 \pm 0.4 \\
1.61 \pm 0.4 \\
142.6 \pm 24.6 \\
144.3 \pm 43.9 \ddagger \\
60.1 \pm 11.2\end{array}$ & $\begin{aligned} 235.2 & \pm 20.7 \\
139.0 & \pm 25.2 \\
66.8 & \pm 4.7 \\
142.8 & \pm 20.0 \\
27.8 & \pm 5.0 \\
0.30 & \pm 0.06 \\
33.3 & \pm 4.1 \S \\
22.0 & \pm 4.0 \\
3.05 & \pm 0.7 \dagger \\
2.11 & \pm 0.4 \\
1.30 & \pm 0.2 \\
147.6 & \pm 51.5 \S \\
149.4 & \pm 49.8 \S \\
75.1 & \pm 17.1 \S \dagger\end{aligned}$ \\
\hline $\begin{array}{l}\text { Normoinsulinemic } \\
\text { Cholesterol* }(\mathrm{mg} / \mathrm{dll}) \\
\text { Trygliceride }^{\star \star}(\mathrm{mg} / \mathrm{dl}) \\
\text { HDL-C }(\mathrm{mg} / \mathrm{dl}) \\
\text { LDL-C }(\mathrm{mg} / \mathrm{dl}) \\
\text { VLDL-C }(\mathrm{mg} / \mathrm{dl}) \\
\text { NEFA }(\mathrm{mEq} / \mathrm{l}) \\
\text { FSH }(\mathrm{IU} / \mathrm{l} /) \\
\text { LH }(\mathrm{IU} / \mathrm{l}) \\
\text { Androstenedione }(\mathrm{nmol} / \mathrm{l}) \\
17-O H P(\mathrm{nmol} / \mathrm{l}) \\
\text { DHEAS }(\mu \mathrm{mol} / \mathrm{l}) \\
\text { Estradiol }(\mathrm{pmol} / \mathrm{l}) \\
\text { Estrone }(\mathrm{pmol} / \mathrm{l}) \\
\text { SHBG }(\mathrm{mmol} / \mathrm{l})\end{array}$ & $\begin{array}{c}221.4 \pm 15.1 \\
143.6 \pm 18.2 \\
49.2 \pm 3.6 \\
143.3 \pm 13.7 \\
29.4 \pm 3.8 \\
0.37 \pm 0.02 \\
65.1 \pm 5.2 \\
45.6 \pm 4.2 \\
1.92 \pm 0.3 \\
1.51 \pm 0.3 \\
1.52 \pm 0.1 \\
41.8 \pm 5.2 \\
48.3 \pm 7.5 \\
42.1 \pm 4.1\end{array}$ & $\begin{array}{c}212.6 \pm 10.9 \\
156.7 \pm 32.9 \\
58.8 \pm 4.2 \\
128.9 \pm 14.3 \\
25.6 \pm 3.6 \\
0.35 \pm 0.10 \\
38.6 \pm 4.2 \ddagger \\
31.9 \pm 4.6 \\
2.18 \pm 0.5 \\
1.21 \pm 0.3 \\
1.24 \pm 0.1 \\
117.5 \pm 17.5 \ddagger \\
112.8 \pm 23.5 \ddagger \\
63.3 \pm 9.4 \pm\end{array}$ & $\begin{array}{c}211.8 \pm 10.2 \\
169.5 \pm 39.2 \\
58.3 \pm 5.2 \\
126.7 \pm 8.6 \S \\
30.2 \pm 4.8 \\
0.28 \pm 0.05 \\
31.6 \pm 3.4 \S \\
23.3 \pm 3.3 \\
2.34 \pm 0.3 \\
1.48 \pm 0.2 \\
1.21 \pm 0.2 \\
127.6 \pm 16.2 \S \\
128.2 \pm 40.8 \S \\
56.7 \pm 11.1\end{array}$ \\
\hline
\end{tabular}

*Conversion factor to SI unit, $0.0258 ;{ }^{* *}$ conversion factor to SI unit, 0.0112 .

$\ddagger P<0.05, \boldsymbol{b}$ compared with $\boldsymbol{a}$; $\S P<0.05, \boldsymbol{c}$ compared with $\boldsymbol{a}$; $\dagger P<0.05$, hyperinsulinemic compared with normoinsulinemic.

transdermal ERT and, when necessary, for dydrogesterone progestin-combined HRT, because of the improvement that can be achieved in glucose homeostasis.

It is difficult to explain by a cause-effect mechanism why some postmenopausal women are hyperinsulinemic, taking into consideration that they have insulin sensitivity and BMI superimposable on those of normoinsulinemic women. The main cause may be ascribed to a reduction in hepatic clearance. The improvement that we observed after 12 and 24 weeks may have been due to hepatic enzymatic induction by transdermal estradiol. In previous studies (19), parenteral estrogen administration was able to produce an increase in plasma estradiol concentrations to more than $700 \mathrm{pmol} / \mathrm{l}$, associated with a $20 \%$ decrease in LDL-C. Moreover, the significant increase in SHBG observed in our study could further support the contention of an impact upon the liver by prolonged transdermal estrogen treatment. In the light of the well known linkage between aging, insulin resistance and the occurrence of impaired glucose tolerance or NIDDM, one can speculate that deterioration in glucose tolerance may be preventable in 
hyperinsulinemic postmenopausal women, as the net positive effect of transdermal therapy on glucose homeostasis in these patients would be an improvement in insulin secretion and metabolism, and in peripheral insulin sensitivity.

In conclusion, this is the first report in which it is shown that physiological transdermal substitution alone, in addition to dydrogesterone combined cyclically, may potentially reduce the exaggerated insulin response to OGTT in postmenopausal hyperinsulinemic women. Further observations are necessary in order better to elucidate this interesting point.

\section{References}

1 Buchler D \& Warren JC. Effects of estrogen on glucose tolerance. American Journal of Obstetrics and Gynecology 1966 95 479-483.

2 Spellacy WN, Buhi WC \& Birk SA. The effect of estrogen on carbohydrate metabolism: glucose, insulin, and growth hormone studies on one hundred and seventy-one women ingesting Premarin, mestranol, and ethinyl estradiol for six months. American Journal of Obstetrics and Gynecology $1972114378-392$.

3 The Writing Group for the PEPI Trial. Effects of estrogen or estrogen/progestin regimens on heart disease risk factors in postmenopausal women: the postmenopausal estrogen/progestin interventions (PEPI) Trial. Journal of the American Medical Association 1995273 199-208.

4 Cagnacci A, Soldani R, Carriero PL, Paoletti AM, Fioretti P, Melis $\mathrm{GB}$ et al. Effect of low doses of transdermal $17 \beta$-estradiol on carbohydrate metabolism in postmenopausal women. Journal of Clinical Endocrinology 199274 1396-1400.

5 Lindheim SR, Presser SC, Ditkoff EC, Vijod MA, Stanczyk FZ, Lobo RA. A possible bimodal effect of estrogen on insulin sensitivity in postmenopausal women and the attenuating effect of added progestin. Fertility and Sterility $199360664-667$.

6 O'Sullivan A \& HO Ken KY. A comparison of the effects of oral and transdermal estrogen replacement on insulin sensitivity in postmenopausal women. Journal of Clinical Endocrinology and Metabolism 199580 1783-1788.

7 Sutter-Dub MT, Dazey B, Hamdan E \& Vergnaud MT. Progesterone and insulin-resistance: studies of progesterone action on glucose transport lipogenesis and lipolysis in isolated fat cells of the female rat. Journal of Endocrinology 198188 455-462.

8 Grodstein F, Stampfer MJ, Manson JAE, Colditz GA, Willet WC Rosner B et al. Postmenopausal estrogen and progestin use and the risk of cardiovascular disease. New England Journal of Medicine $1996335453-461$.

9 Chetkowski RJ, Meldrum DR \& Steingold KA. Biological effect of transdermal estradiol. New England Journal of Medicine 1986314 1615-1620.
10 De Fronzo RA, Tobin JD \& Andres R. Glucose clamp technique: a method for quantifying insulin secretion and resistance. American Journal of Physiology 1979237 214-223.

11 National Diabetes Data Group. Classification and diagnosis of diabetes mellitus and other categories of glucose intolerance. Diabetes $1979281039-1057$.

12 Lanzone A, Fulghesu AM, Fortini A, Cutillo G, Cucinelli F, Di Simone N, Caruso A et al. Effect of opiate receptor blockade on the insulin response to oral glucose load in polycystic ovarian disease. Human Reproduction 19916 1043-1049.

13 Bonadonna RC, Groop L \& Kraemer N. Obesity and insulin resistance in humans: a dose response study. Metabolism $199039452-459$.

14 Faber OK, Christensen K \& Ketlem H. Decreased insulin removal contributes to hyperinsulinemia in obesity. Journal of Clinical Endocrinology and Metabolism 198153 618-621.

15 Bergman RN, Finegood DT \& Ader M. Assessment of insulin sensitivity in vivo. Endocrine Reviews 19856 45-75.

16 Walsh BW, Shiff I, Rosner B, Greemberg L, Rawnikar W \& Shacks FM. Effects of postmenopausal estrogen replacement on the concentrations and metabolism of plasma lipoproteins. New England Journal of Medicine 1991325 1196-1204.

17 Lobo RA. Effects of hormonal replacement on lipids and lipoproteins in postmenopausal women. Journal of Clinical Endocrinology and Metabolism 199173 925-930.

18 Jensen J, Riis BJ, Strom V, Nilas L \& Christiansen G. Long term effects of percutaneous estrogen and oral progesterone on serum lipoprotein in postmenopausal women. American Journal of Obstetrics and Gynecology 1987156 66-71.

19 Reaven GM. Role of insulin resistance in human disease. Diabetes $1988371595-1607$.

20 Hjortland MC, McNamara PM \& Kannel WB. Some atherogenic concomitants of the menopause. The Framingham study. American Journal of Epidemiology 1976103 304-311.

21 Matthews K, Meilahn E, Kuller L, Kelsey S, Caggiula A \& Wing R. Menopause and risk factors for coronary heart disease. New England Journal of Medicine 1989321 641-646.

22 Walton C, Godsland I, Proudler A, Wynn V \& Stevenson CJ. The effects of menopause on insulin sensitivity, secretion and elimination in nonobese healthy women. European Journal of Clinical Investigation 199323 466-473.

23 Godsland IF, Crook D, Stevenson JC, Collins P, Rosano GMC, Less $\mathrm{B}$, Sidhu $\mathrm{M}$ et al. The insulin resistance syndrome in postmenopausal women with cardiological syndrome X. British Heart Journal 1995 74 47-52.

24 Lobo RA, Pickar JH, Wild RA, Walsh B \& Hirvinen E. Metabolic impact of adding medroxyprogesterone acetate to conjugated estrogen therapy in postmenopausal women. Obstetrics and Gynecology $199484987-995$.

25 The Cleyn K, Buytaert P \& Coppens M. Carboydrate metabolism during hormonal sobstitution therapy. Maturitas 198911 235242 .

Received 17 June 1998

Accepted 11 November 1998 